\title{
Human Parainfluenza Virus 1
}

National Cancer Institute

\section{Source}

National Cancer Institute. Human Parainfluenza Virus 1. NCI Thesaurus. Code C14254.

A single-stranded, negative-sense RNA virus of the paramyxovirus group that causes

croup in children. 